\title{
Mechatronics in the Netherlands
}

\author{
Job van Amerongen, Member, IEEE, and Wim Jongkind
}

(Invited Paper)

\begin{abstract}
This article assesses the present situation of mechatronics in the Netherlands. After a short historical survey, it describes the postgraduate "mechatronic designer course," introduced in 1991. It deals with the principles of this course and how these principles have been implemented. Also, the activities of the Dutch government in cooperation with the industrial mechatronics community to enhance the awareness of mechatronics, especially directed toward small and medium-sized enterprises (SME's) is described.
\end{abstract}

\section{INTRODUCTION}

I $\mathrm{N}$ the Netherlands the interest of industry for mechatronics is growing. This is the result of the early recognition of the importance of mechatronics by universities and polytechnics, as well as the stimulus given by the government. Several mechatronic programs have been available on different levels of education for some years. This has resulted in a growing outflow of engineers, experienced in mechatronic design. In 1989, the Mechatronic Research Center Twente started its activities after receiving a grant from the government for starting innovative research. This cooperation of four different departments (Mechanical and Electrical Engineering, Applied Mathematics, and Computer Science) of the University of Twente initiated common research projects and provided opportunities for M.Sc. students to work in a mechatronic, multidisciplinary environment. The University of Twente (coordinator) and the Eindhoven University of Technology started in 1991 the "mechatronic designer course"-a two-year postgraduate program. Recently Delft University of Technology also got involved. The program mainly attracts students with a background in mechanical and electrical engineering, but other engineering students can be admitted as well. Also at other levels of education mechatronic programs have been started, but in this paper emphasis is on the academic program.

In 1990, the Ministry of Economic Affairs carried out a survey of mechatronic activities in the Netherlands, followed by a program to stimulate mechatronic research projects $(50 \%$ of the research activities could be sponsored) and by financing the activities of the Mechatronics Platform. The latter is a meeting place of people from industry, research organizations, and educational institutes. This platform launched an intensive campaign in order to enhance the awareness in industry of the potential of mechatronics. This campaign included

Manuscript received February 18, 1996; revised April 1, 1996.

J. van Amerongen is with the Department of Electrical Engineering, University of Twente, 7500 AE Enschede, Netherlands.

W. Jongkind is with the Department of Electrical Engineering, Delft University of Technology, 2628 CD Delft, Netherlands.

Publisher Item Identifier S 1083-4435(96)05079-X. advice visits by mechatronic experts and an information campaign, especially aiming at small and medium-sized enterprises (SME's). The platform was also involved in awarding prizes (the Mechatronics Award) for the most innovative mechatronic products, as well as for the best thesis on a mechatronic subject by a student. These prizes should also make clear what is to be considered a good "mechatronic" design. Not every mechanical construction that is extended with an electronic controller is a mechatronic system. A general accepted definition of mechatronics in the Netherlands is the definition formulated by the Industrial Research and Development Advisory Committee of the European Union (IRDAC):

The term "mechatronics" refers to a synergistic combination of precision engineering, electronic control and systems thinking in the design of products and manufacturing processes. It is an interdisciplinary subject that both draws on the constituent disciplines and includes subjects not normally associated with one of the above.

Most essential in this definition is the "systems approach." This implies that the system is designed and optimized as a whole and not in sequential steps. By concentrating on a limited application area, a mechatronic designer should have enough domain specific knowledge to come to really advanced products. Mechatronic design also implies team work. Specialists with a background in mechanical and electrical engineering, control and computer engineering should cooperate in a team, in all phases of the design, to come to a synergistic combination. Finally a good design philosophy is essential.

A more concise definition is given by Buur [2]:

Mechatronics is a technology which combines mechanics with electronics and information technology to form both functional interaction and spatial integration in components, modules, products and systems.

\section{MECHATRONICS EDUCATION}

\section{A. General Characteristics}

It is noticeable that the industry has an increasing interest for mechatronic designers. In order to design products and production processes, characterized by fast response times and high precision, one cannot be satisfied with a basically mechanical design to which later a control system has been added. Only an integrated design based on the knowledge of construction possibilities, knowledge of electronics and computer hardware, control engineering, control theory and 
computer science can lead to advanced products, (van Amerongen et al. [1]). Although the mechatronic designer does not have to be a specialist in all the concerned technical areas, he or she should have enough knowledge of the other disciplines than the one which is his or hers major study, in order to function with success in a mechatronic design team. During the undergraduate phase of the curricula in, for instance, mechanical or electrical engineering this multidisciplinary character is not deeply stressed. Therefore, the curriculum for the postgraduate mechatronic design course has a multidisciplinary character.

\section{B. The Mechatronic Designer Course}

The mechatronics designer course is a two-year postgraduate course for graduates with a background in electrical and mechanical engineering, computer science, and related study areas such as applied physics. At present the course is offered by the University of Twente and the Technical Universities of Eindhoven and Delft. At the University of Twente the mechatronics activities are concentrated in the Mechatronics Research Center Twente (MRCT), a cooperation of the departments of mechanical engineering, electrical engineering, applied mathematics, and computer science. The Technical University of Eindhoven has concentrated its efforts at the Department of Electrical Engineering and the Department of Mechanical Engineering. At Delft University of Technology, the Mechatronic Activities are concentrated in the Department of Mechanical Engineering and Maritime Technique and the Department of Electrical Engineering.

Since candidates can have different backgrounds, broadening and deepening of skills and knowledge depends on the individual student's background. The first year is mainly filled with courses and smaller projects. During a so-called homogenization phase, deficiencies in mechanical and electrical engineering as well as in mathematics or computer science can be dealt with. In addition, courses are required that deepen the knowledge in technical subjects, as well as in project planning, oral and written communication, management, etc. During the development of the course the industry has been involved in discussing the content of the course. The second year is completely devoted to a major real mechatronic design assignment, to be performed in close cooperation with the industry.

The quality of all designer programs in the Netherlands is guarded by the National Committee for the Certification of Designers (CCTO), consisting of members of the academic community, as well as from industry. A new program obtains a preliminary certification, if it is set up according to some basic requirements. After completion of about ten projects, the quality of the designs is judged by referees from industry in order to obtain a "permanent" certification. The latter has to be renewed every five years. The ease with which graduates obtain a job-as a measure of the needs of industry for this type of training--plays a role in this process, in addition to the technical content of the program. For the mechatronic program this is no problem. The graduates appear to be very attractive for a variety of companies and easily find jobs.

\section{Aims of the Mechatronic Designer Course}

The aims of the course are:

I) Broadening: A student entering the course should collect the knowledge and skills needed to operate as a mechatronic designer in a design team. Undergraduate courses from a department other than the one the student graduated in may have to be followed in order to get a broad background.

2) Deepening: Next to broadening the knowledge, a deepening of subjects already studied originally during his undergraduate major is also necessary to bring the knowledge and skills of the original major curriculum to the right level.

3) Integration: A third aim is to integrate the subjects taught, by means of performing a mechatronic design project in a practical industrial environment.

4) Management, etc.: Finally the curriculum aims to deepen and broaden the knowledge and skills on subjects such as project management, conducting meetings, oral and written presentations, communication, etc.

The postgraduate mechatronic designer course does not aim to reach a complete homogeneous end product in which, for instance, graduated electrical or mechanical engineers reach the same end terms. Rather a certain homogenization is necessary. The before-mentioned undergraduate courses form a part of this homogenization.

\section{Prerequisites}

The postgraduate course can be followed by graduates under the following restrictions:

- The study results during graduation or results obtained during employment in industry are of a high level. Important in this context are the talents and creativity of the candidate. As a reference, the top $30 \%$ of the M.Sc. programs should qualify.

- Prerequisites are graduation in one of the following major technical studies:

mechanical engineering;

electrical engineering;

computer science;

physics;

applied mathematics;

polytechnics: if the candidate has the ability to follow the study, shown during her or his functioning employed in an industrial job, such in agreement with the admission committee.

- The chosen courses are in agreement with the requirements set by a national program committee for the mechatronic designer program.

\section{E. Course Goals}

A mechatronic designer has to:

- be able to function creatively in a multidisciplinary environment and has to be able to contribute expert knowledge to the design of a mechatronic system;

- have knowledge of the opportunities and limits of mechatronic constructions, sensor technology, actuators, and control systems; 
- to reach a conclusion if several different options are available (for example a mainly mechanic or a mainly electronic solution or realization);

- have knowledge of costs, quality, safety, and suitability for industrial production;

- have knowledge of marketing, budgeting, investment, written and oral presentation, and project management;

- have adequate knowledge of the different areas of importance needed for the design of a mechatronic system (from mechanical engineering subjects such as kinematics, mechanisms, tooling, tribology, finite elements, and methodological design; from electrical engineering subjects as modeling and simulation, automatic control, sensors and actuators, electrical drives, electronic circuit design, computer hardware; from computer science subjects such as operating systems, programming, computer networks and from applied mathematics subjects such as system and control theory and stochastics);

- have a good basic knowledge in all these areas in order to enable him or her to fully function as a partner in a mechatronic design team and/or to lead such a team, while he or she should have a deeper specialistic knowledge in at least one of the areas. On the basis of knowledge and experience, he or she should be able to convince others, with a less multidisciplinary education, of the benefits of a mechatronic approach and solution.

\section{F. Content and Structure of the Postgraduate Course}

The curriculum for mechatronic designer takes two years to finish. The first year has been reserved for the cursory part and consists of:

1) a selection of courses in the fields of mechatronics, mechanical and electrical engineering, applied physics, computer science, and applied mathematics as well as in nontechnical subjects;

2) a choice from:

a) literature study concerning a specific subject within the area of mechatronics, or

b) a short study or course outside the university of origin with the aim to gather knowledge about a new approach or development in the area of mechatronics or design. This study has to result in a written report and has to be orally presented.

The main part of the curriculum in the first year consists of existing courses of the participating departments of the three universities. A few new courses have been developed and added to the list of study subjects. The mechatronic designer has to follow a number of compulsory courses and a number of free elective (technical as well as nontechnical) courses. The study plan is made in agreement with the admission committee and the student.

Both years have a study load of 43 credit points/year (40 hours/credit). Typical courses for the homogenization phase are (each course is 2-3 credit points):

From mechanical engineering:

1) materials;

2) production systems;
3) theoretical mechanics;

4) dynamic behavior of systems;

5) construction principles.

From electrical engineering:

1) electronics;

2) introduction to digital technique;

3) microcomputers;

4) introduction to mechatronics.

Whether a student has to follow a part or all of these compulsory courses, depends on the background. The other (elective) courses have to be taken from a selection of the curricula of mechanical engineering, electrical engineering, computer science, applied mathematics, business administration, and humanities. Main emphasis is on dynamic systems, design, budgeting, and planning.

The second year is dedicated to the realization of a realistic, industrial design assignment in the field of mechatronics. The assignment is aimed at getting experience in describing a problem, modeling, choice and application of the analysis method, the synthesis, the assimilation of the results of the analysis, writing a report, and the oral presentation. Often the realization of the design and experimenting with the prototype design are of utmost importance. The design assignment is preferably to be performed in cooperation with industry for example in the form of contract research. During the realization of this assignment the student will have at least 75 contact hours with an experienced designer.

A typical example of such a project was the very first project. This project was carried out by three students of the mechatronics designer's course at the University of Twente, in cooperation with Philips in Eindhoven (Netherlands). One student had an electrical engineering background; the other two had a background in mechanical engineering. The design assignment was to develop a device that could place surface mounted devices (SMD's) with high speed and accuracy on a printed circuit board. After placing, the leads of the SMD should be welded to the printed circuit board by means of a laser beam, to replace the conventional soldering. One student was mainly responsible for the laser welding, the other two for the placing device. The three together were responsible for the project as a whole. It was requested that the placing device should be based on an electrical servo mechanism, to replace the present pneumatic equipment. In an early stage it was decided to use an ac motor because of its robustness. This motor should be able to rotate and translate simultaneously. Problems to be solved were: the construction of the motor, the development of a contact free sensor that could accurately measure the rotation while allowing up to $30-\mathrm{cm}$ translation, the position and angle control, and minimization of the power dissipation, etc. After one year the project was successfully completed. A working prototype of the motor was realized as well as a demonstration of the laser welding system. The process conditions for the latter were determined and patents were applied for the angle sensor and the motor control system. 


\section{CoOperation OF Government, INDUSTRY AND EDUCATIONAL INSTITUTES}

\section{A. History}

In 1990, the Ministry of Economic Affairs initiated a technology search into mechatronic sensors and actuators. It was concluded that "although there was enough knowledge in the educational and research institutes as well as infrastructure, the spread of the mechatronic knowledge into SME's especially the machine building sector did give reason to worry." Therefore, the Ministry took initiatives which have led to a national mechatronics platform. Participants in this platform are SME's, universities and polytechnics, the national research organization for applied technology (TNO), technology innovation centers (CME), and engineering consultants as well as large companies (such as Philips). Main aims of the platform are to enhance the awareness and understanding of mechatronics, and to stimulate application of mechatronics within Dutch enterprises. Other aims are to act as a knowledge source and a meeting place. The creation of a network of companies and institutes involved in mechatronic design was another aim.

There was less need to stimulate the awareness for mechatronics in larger companies, such as Philips. On the contrary, these companies can be seen as pioneers of mechatronics. One of the often cited examples of a mechatronic product is the compact disc (CD) player, a Philips invention. Their presence in the platform is important as a source of information.

The first actions of the platform included the following activities.

- Six promotion articles were published in the Dutch technical press emphasizing six examples of mechatronic designs.

- A mechatronic information guide was produced containing addresses of research institutes and enterprises, active in mechatronics design.

- The "mechatronics trophy" was created and given as a price to SME's for designing the best mechatronic product of the year, and to students, for performing the best thesis work on mechatronics. The award is given to the winners during a large exhibition taking place each year and is widely published.

\section{B. Enhancement of Awareness}

The next step to enhance the awareness of mechatronics for the Dutch industry was to launch a publicity campaign. A campaign team was formed consisting of members from, among others, the Federation of Metal and Electrical Industries, the Ministry of Economic Affairs, Innovation Centers, TNO, and an advice bureau. The implementation of the campaign was led by so called Innovation Centers.

Campaign Activities: The two main aims of the campaign were:

- $25 \%$ of the industries the campaign is aimed at should know within one and a half year what is meant by mechatronics;
- $10 \%$ of the industries has to have started with mechatronic application projects.

The group of industries aimed at were industries with more than five and less than thousand employees, in total about 3000 enterprises. The industries approached are divided over the following market sectors:

- machine industry (1749);

- electrical and electronic industries (675);

- transport machine industries (219);

- instruments and optical industries (280);

- others (63).

To reach the industries a variety of publicity approach methods were applied. At first a telephone campaign took place to enhance the awareness, obtain the status quo, supply information and make agreements of the follow up. At the same time an intensive publicity campaign in the Dutch technical journals was initiated.

The follow-up did consist of:

- sending written mechatronics information by post;

- organizing regional information meetings. During these meetings objectives of the platform were presented, the meaning of mechatronics was explained, two mechatronic design examples were presented and the meetings were closed with informal discussions. A total of 9 meetings were held, 200 industries, with 20-50 employees participated, mainly R\&D departments took part;

- advice given by experts on request;

- a video tape with mechatronic examples which could be obtained on request;

- organizing and taking part in presentations on national meetings and exhibitions.

After about one year from the start of the campaign attention was focused on entities which showed interest but who were not involved in a follow-up action yet. These industries received a mailing attending them on the opportunity to receive the video presentation about mechatronics. One-and-a-half years after the start a poll was held to inventory the awareness of mechanical approaches of which the result is shown below.

\section{Results}

As a result of the campaign it was found that (Schurgers and Derde, 1995):

- 54\% of the enterprises contacted had no idea or knowledge about mechatronics.

- $19 \%$ had the wrong idea (people that write mechatronics as "MEGAtronics").

- $20 \%$ had a clear picture.

During the follow-up of the campaign. the results included the following:

- $41 \%$ became interested after explanation of the meaning of mechatronics.

- $50 \%$ received the information guide.

- $21 \%$ wanted to take part in informative presentations.

- $7 \%$ was interested in discussing their problem with an advisor.

- $5 \%$ was interested in contacting a mechatronics specialist. 
This shows that the follow-up was of utmost importance in enhancing the awareness. A few weeks after the video information was sent, a poll took place. It showed that after asking the question whether mechatronic applications had increased:

- $19 \%$ were already involved in an advanced state.

- $31 \%$ had just started.

- $21 \%$ had plans to start soon.

- $29 \%$ had no plans to start.

At the end of the campaign it can be concluded that the aims to significantly increase the awareness and application of mechatronics has been reached. Cooperation between the entities taking part (governmental, industrial, etc.) has increased and will be continued for the foreseeable future.

\section{CONClusion}

In recent years the awareness and interest of the industry for mechatronics has increased. The three technical universities in the Netherlands have contributed to this development in several ways, but especially by means of the two-year, postdoctoral mechatronic designer course, introduced in 1991. Graduates of this course easily find good jobs in industry. The industrial partners, involved in the second year of this course, react positively on this cooperation and are enthusiastic on the design projects realized. As a result of these projects several designs have been successfully completed and realized as a product. Several patents have been obtained by the industrial partners.

\section{REFERENCES}

[1] J. van Amerongen, A. W. P. Bakkers, P. C. Breedveld, and T. J. A. de Vries, "Tools for mechatronic design," in Int. Symp. Enabling Objects for Industry, Univ. Twente, 1994, pp. 16-21.

[2] Buur, "A theoretical approach to mechatronics design," Ph.D. dissertation, Technical Univ. Denmark, Lyngby, Denmark, 1990.

[3] "Opinion on R\&D needs in the field of mechatronics," Industry R\&D Advisory Committee of the European Community, 1986.

[4] A. M. J. Schurgers and M. W. Derde, "National project for the awareness of mechatronics (in Dutch)," carried out for the Mechatronics Platform by Innovation Centra Network in the Netherlands, Final Rep. for the period May 1993-Dec. 1994, Feb. 1995.

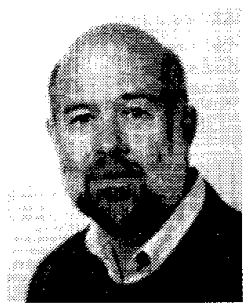

Job van Amerongen (M'90) received the M.Sc. degree in electrical engineering from Delft University of Technology, Delft, the Netherlands, in 1971, and obtained a Ph.D. degree in 1982

From 1971 to 1973, he did his military service as officer in the Royal Netherlands Navy. From 1973 to 1987 , he was assistant and associate professor at the Control Laboratory of the Department of Electrical Engineering of Delft University of Technology, where he worked on applications of modern control theory, especially model reference adaptive control, in ship control systems and electrical power production systems. Since 1987. he has been a professor in Control Engineering in the Department of Electrical Engineering at the University of Twente, Enschede, the Netherlands. His current research interests are applications of modern control theory, especially intelligent control, in mechatronic systems. As head of the control laboratory he is also involved in the research in modeling and simulation of dynamical systems and in real-time parallel computing. He is director of the Mechatronics Research Center Twente, a cooperation of four departments of the University of Twente. Presently he is also Dean of the Department of Electrical Engineering. He is coauthor of many papers on adaptive and intelligent control systems and automatic steering of ships, coauthor of a book on adaptive control systems, and author of three courses on systems and control of the Dutch Open University.

Dr. van Amerongen is a member of the Royal Institute of Engineers in the Netherlands.

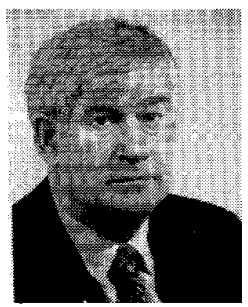

Wim Jongkind received the M.Sc. degree from Delft University of Technology, Delft, the Netherlands, and performed Ph.D. research at the same university.

He was a research fellow at the European Space Agency and project engineer at Fokker Space Systems involved in the design of the attitude control system for the Anglo/American/Dutch IRAS satellite. He is currently an Associate Professor at the Control Laboratory, Faculty of Electrical Engineering. Delft University of Technology, a member of the Faculty Robotics Committee, coordinator of EC TELEMAN project 18 , chairman of the Faculty Committee for laboratory exercises, and coordinator of the second-phase study program Mechatronic Designer for Delft University of Technology. He was also one of the organizers of the EC TELEMAN Congresses in 1994 and 1995. He is the author and coauthor of more than 60 publications. His fields of research interest are: mechatronics, telemanipulation, sensor-based robotics, and applied control in industrial applications. 